\title{
Anti-cholinesterases and memory improving effects of Vietnamese Xylia xylocarpa
}

\author{
Linh My Thi Lam', Mai Thanh Thi Nguyen ${ }^{1,6 *}$, Hai Xuan Nguyen', Phu Hoang Dang ${ }^{1}$, Nhan Trung Nguyen', \\ Hung Manh Tran ${ }^{1}$, Hoa Thi Nguyen², Nui Minh Nguyen², Byung Sun Min ${ }^{3}$, Jeong Ah Kim, Jae Sue Choi ${ }^{5}$ \\ and Mao Van Can ${ }^{2^{*}}$
}

\begin{abstract}
Background: Alzheimer's disease (AD) is the most common cause of dementia among the elderly and is characterized by loss of memory and other cognitive functions. An increase in AChE (a key enzyme in the cholinergic nervous system) levels around $\beta$-amyloid plaques and neurofibrillary tangles is a common feature of AD neuropathology. Amnesic effects of scopolamine (acetylcholine receptor antagonist) can be investigated in various behavioral tests such as Morris water maze, object recognition, Y-maze, and passive avoidance. In the scope of this paper, we report the anti-AChE, anti-BChE properties of the isolated compound and the in vivo effects of the methanolic extract of Xylia xylocarpa (MEXX) on scopolamine-induced memory deficit.
\end{abstract}

Results: In further phytochemistry study, a new hopan-type triterpenoid, (3ß)-hopan-3-ol-28,22-olide (1), together with twenty known compounds were isolated (2-21). Compound 1, 2, 4, 5, 7-9, and 11-13 exhibited potent acetylcholinesterase (AChE) inhibitory activity in a concentration-dependent manner with $I C_{50}$ values ranging from 54.4 to $94.6 \mu \mathrm{M}$. Compound $\mathbf{1 3}$ was also shown anti-butyrylcholinesterase (BChE) activity with an $I C_{50}$ value of $42.7 \mu \mathrm{M}$. The Morris water Y-maze, Y-maze, and object recognition test were also carried out.

Conclusions: It is noteworthy that MEXX is effective when administered orally to mice, experimental results are consistent with the traditional use of this medicinal plant species.

Keywords: Xylia xylocarpa, Hopan-ol-olide, Acetylcholinesterase, Butyrylcholinesterase, Improving memory effects

\section{Background}

Alzheimer's disease (AD), a degenerative brain disorder leading to dementia, is one of the most common disorders of old age, affecting nearly 4 million individuals in the US. Typical clinical features of Alzheimer's disease are memory loss, language deterioration, reduced visual space, sensation disorders and epilepsy advocacy gradual progression of terminal illness $[1,2]$. There are several theories about the cause of Alzheimer's disease, in which the theory about the decline of acetylcholine is the most widely accepted and is the basis for the current development of the drugs of Alzheimer's disease. The research

\footnotetext{
*Correspondence: nttmai@hcmus.edu.vn; canvanmao@yahoo.com ${ }^{1}$ Faculty of Chemistry, University of Science, Vietnam National UniversityHochiminh City, 227 Nguyen Van Cu, District 5, Hochiminh City, Vietnam 2 Vietnam Military Medical University, Hadong District, Hanoi, Vietnam Full list of author information is available at the end of the article
}

on Alzheimer's patients demonstrated that cholinergic abnormalities correlated with the degree of memory and cognitive impairment $[2,3]$. These findings have led to the treatment of Alzheimer's disease by increasing the activity of the cholinergic system (acetylcholinesterase, AChE, inhibitory mechanism) [2, 3]. Recently, some research found that $\mathrm{AChE}$ is also related to the formation of amyloid plaques and neurofibrillary tangles [4].

Xylia xylocarpa (Roxb.) Taub. is a perennial tree belonging to the family Fabaceae, which is sparsely distributed in Burma, Vietnam, Cambodia, and India. In Vietnam, X. xylocarpa is known as "Cam Xe"; the bark, heartwood, and flower have been used as Vietnamese traditional medicines for the treatment of dementia, duodenal, stomach pain, vomiting, diarrhoea, gonorrhoea, leprosy, and rheumatism [5]. Previously, the chemical constituents of the wood of X. xylocarpa have been 
reported some flavan-3-ols including monomer, dimer, and trimer of epiafzelechin [6]. Our preliminary screening study also revealed that the methanolic extract of the wood of $X$. xylocarpa exhibited significant AChE and BChE (butyrylcholinesterase) inhibitory activities with $\mathrm{IC}_{50}$ values of 16.17 and $7.13 \mu \mathrm{g} / \mathrm{mL}$, respectively. In the present study, we report the cognitive-enhancing effect of the methanolic extract of $X$. xylocarpa (MEXX) on amnesic mice induced by scopolamine in vivo. In addition, the isolation of MEXX was carried out, a new hopan-type triterpenoid, (3 $\beta$ )-hopan-3-ol-28,22-olide (1) was isolated together with twenty known compounds (2-21). We also reported the anti-AchE, anti-BChE properties of the isolated compound herein.

\section{Results and discussions Chemistry}

The MEXX was suspended in $\mathrm{H}_{2} \mathrm{O}$ and then successively partitioned with hexane, EtOAc, and $\mathrm{BuOH}$ to yield hexane, EtOAc, $\mathrm{BuOH}$ and $\mathrm{H}_{2} \mathrm{O}$ fractions, respectively. Separation and purification of EtOAc soluble fraction led to the isolation of a new hopan-ol-olide named ( $3 \beta$ )-hopan3-ol-28,22-olide (1), together with twenty known compounds (2-21). These known compounds were identified as lupeol (2) [7]; 28-norlup-20(29)-ene-3 $\beta, 17 \beta$-diol (3) [8]; betulin (4) [9]; 28-norlup-20(29)-ene-3 $\beta$-hydroxy$17 \beta$-hydroperoxide (5) [10]; betulinaldehyde (6) [11]; betulinic acid (7) [12]; betulonic acid (8) [12]; oleanolic acid (9) [13]; $3 \beta$-hydroxy-18 $\alpha$-olean-28,19 $\beta$-olide (10) [14]; $3 \beta$-formyloxy-18 $\alpha$-oleanano-28,19 $\beta$-lactone (11) [15]; chrysophanol (12) [16]; 2,6-dimethoxyl- $p$-benzoquinone (13) [17]; ferulic acid (14) [18]; methyl ferulate (15) [19]; methyl 3-(4-hydroxyphenyl)-2-methoxycarbonylpropionate (16) [20]; protocatechuic acid (17) [21]; vanillic acid (18) [22]; vanillin (19) [23]; methyl gallate (20) [24]; and syringic acid (21) [22] (Fig. 1) based on the spectroscopic analysis and comparison with literature data.

Compound 1 exhibited an $[\mathrm{M}+\mathrm{H}]^{+}$and $[\mathrm{M}+\mathrm{Na}]^{+}$ peak at $m / z 457.3674$ and 479.3482 , respectively, in the positive HR-ESI-MS, corresponding to the molecular formula $\mathrm{C}_{30} \mathrm{H}_{48} \mathrm{O}_{3}$. The ${ }^{13} \mathrm{C}$ NMR spectrum of compound 1 showed thirty carbon signals, including one lactone carbonyl carbon $\left(\delta_{\mathrm{C}} 175.9\right)$, one hydroxylated methine $\left(\delta_{\mathrm{C}} 79.1\right)$, and one oxygenated tertiary carbon $\left(\delta_{\mathrm{C}} 83.4\right)$. Together with the HSQC analysis, all the remaining carbon signals were identified as five methines, ten methylenes, five quaternary carbons and seven tertiary methyl groups. The ${ }^{1} \mathrm{H}$ NMR spectrum of compound $\mathbf{1}$ also exhibited an oxygenated methine proton signal at $\delta_{\mathrm{H}} 3.19$ (dd, $J=11.4$ and $4.8 \mathrm{~Hz}, \mathrm{H}-3$ ) and seven singlet methyl signals $\left(\delta_{\mathrm{H}} 1.46,1.33,0.96,0.94,0.93,0.83,0.76\right)$. Based on the analysis of these spectra, compound 1 was suggested to be an hopan-type triterpenoid $[25,26]$.
The location of hydroxyl group was deduced to be at $\mathrm{C}-3$, based on the HMBC correlations between the oxygenated methine proton $\mathrm{H}-3$ and the methylene carbon $\mathrm{C}-1\left(\delta_{\mathrm{C}} 39.1\right)$. The HMBC cross-peaks from Me-23 $\left(\delta_{\mathrm{H}} 0.96\right)$ and $\mathrm{Me}-24\left(\delta_{\mathrm{H}} 0.76\right)$ to the hydroxylated carbon $\mathrm{C}-3\left(\delta_{\mathrm{C}} 79.1\right)$; and the splitting patterns of proton $\mathrm{H}-3$ also indicated the hydroxyl group was attached to $\mathrm{C}-3$. The ester carbonyl group was located at $\mathrm{C}-28$ due to the $\mathrm{HMBC}$ correlations between the methine proton $\mathrm{H}-13 / \mathrm{H}-17$ and the carbonyl carbon $\mathrm{C}-28$. The tertiary methyl protons $\mathrm{H}-29$ and $\mathrm{H}-30$ exhibited simultaneously $\mathrm{HMBC}$ correlations with the oxygenated tertiary carbon $\left(\delta_{\mathrm{C}} 83.4\right)$, these was carbon $\mathrm{C}-22$. Based on the chemical shift of C-22 and C-28 [25], it is clear that the lactone ring was formed between these carbons. Combining the ${ }^{1} \mathrm{H}-$ and ${ }^{13} \mathrm{C}$ NMR data (Table 1) with the HSQC, COSY and $\mathrm{HMBC}$ analysis (Fig. 2), the skeletal structure of $\mathbf{1}$ was confirmed as a hopan-3-ol-28,22-olide. The proton $\mathrm{H}-3$ appeared as a doublet of doublets $\left(\delta_{\mathrm{H}} 3.19, J=11.4\right.$ and $4.8 \mathrm{~Hz}$ ) that indicating an axial position of this proton. In the NOESY spectrum (Fig. 2), the correlated signals were observed between $\mathrm{H}-3$ /equatorial $\mathrm{H}-2, \mathrm{H}-3 / \mathrm{H}-5, \mathrm{H}-3 /$ $\mathrm{H}-23$ indicating that the $3-\mathrm{OH}$ group was $\beta$-equatorial orientation. The NOESY spectrum also exhibited the correlations of $\mathrm{H}-24 / \mathrm{H}-25, \mathrm{H}-25 / \mathrm{H}-26, \mathrm{H}-13 / \mathrm{H}-26$, and $\mathrm{H}-9$ / $\mathrm{H}-27$; these observations confirmed four rings $\mathrm{A}, \mathrm{B}, \mathrm{C}$, and D were trans-fused. The NOE correlations between $\mathrm{H}-13 / \mathrm{H}-17$ and $\mathrm{H}-17 / \mathrm{H}-21$ confirmed the $\beta$-equatorial orientation of $\mathrm{H}-21$. Thus, the structure of compound 1 was elucidated to be $(3 \beta)$-hopan-3-ol-28,22-olide.

\section{Biological assay}

The isolated compounds were tested for their AChE and $\mathrm{BChE}$ inhibitory activities at various concentrations using berberin, a known inhibitor of AchE isolated from many plant species, as a positive control (Table 2). In the AChE inhibition assay, compounds 1, 2, 4, 5, 7-9, and 11-13 showed the moderate activity on the inhibition of $\mathrm{AChE}$ with the $\mathrm{IC}_{50}$ values ranging from 54.4 to $94.6 \mu \mathrm{M}$, compared with berberine $\left(\mathrm{IC}_{50 \mathrm{o}}\right.$ of $\left.0.67 \mu \mathrm{M}\right)$. Regarding to the $\mathrm{BChE}$ inhibition, compound $\mathbf{1 3}$ showed the inhibitory effects against $\mathrm{BChE}$ with an $\mathrm{IC}_{50}$ value of $42.7 \mu \mathrm{M}$, compared with the positive control berberine $\left(\mathrm{IC}_{50}\right.$ of $24.5 \mu \mathrm{M})$.

Since MEXX showed potent inhibition activity against ChE enzymes in the primary experiments with the $\mathrm{IC}_{50}$ value of $16.17 \mu \mathrm{g} / \mathrm{mL}$, the in vivo effects of MEXX on scopolamine-induced memory deficit were investigated by using the Y-maze task. A significant group effect was observed in spontaneous alternation behaviors [F (4, $55)=10.859, P<0.001]$. Spontaneous alternation (\%) in the scopolamine-treated group was significantly lower than that in the vehicle-treated control group (Fig. 3a, 


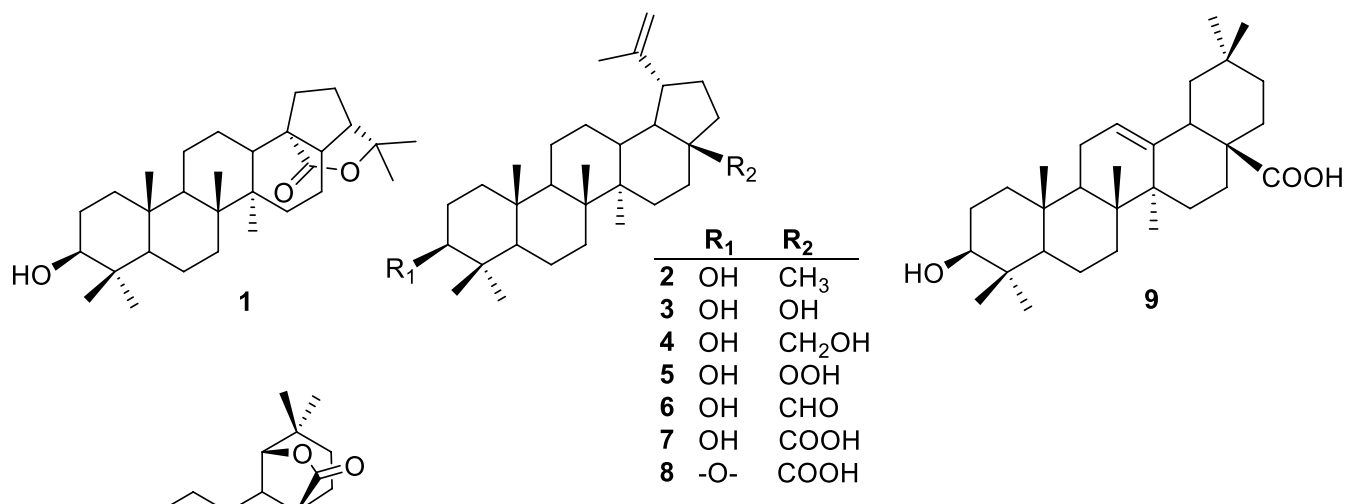<smiles>Cc1cc(O)c2c(c1)C(=O)c1cccc(O)c1C2=O</smiles>

12<smiles>COC1=CC(=O)C=C(OC)C1=O</smiles>

13

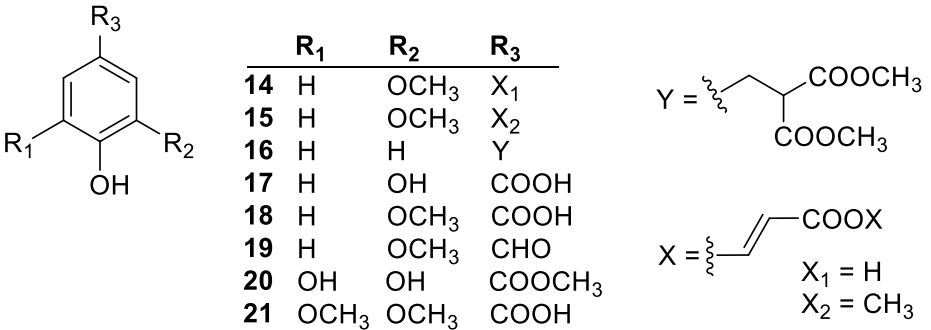

Fig. 1 Chemical structures of isolated compounds (1-21) from the wood of $X$. xylocarpa

$P<0.001)$, and this spontaneous alternation reduction was significantly ameliorated following MEXX administration $(100 \mathrm{mg} / \mathrm{kg}$, p.o.) (Fig. 3a, $P<0.01)$. However, the mean numbers of the arm entries were similar in all experimental groups (Fig. 3b), which demonstrated that locomotor activity was not affected by MEXX.

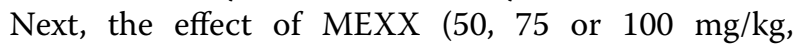
p.o.) on spatial learning was evaluated using the Morris water maze task. A repeated measures two-way ANOVA revealed that there were significant group effects for days $[\mathrm{F}(4.099,45.088)=46.944, P<0.001]$, $[\mathrm{F}(3.788,41.666)=31.557, P<0.001]$ and treatment groups $[\mathrm{F}(2.408,26.483)=34.871, P<0.001]$, [F $(3.555$, $39.106)=45.942, P<0.001]$ on training-trial escape latencies and swimming distances, respectively. As shown in Fig. 2, the scopolamine-treated group $(1.5 \mathrm{mg} /$ $\mathrm{kg}$, i.p.) exhibited longer escape latencies and swimming distances than did vehicle-treated controls from days 3 to 7 (Fig. 4a, b; $P<0.01$ and $P<0.001)$. MEXX (50 mg/ $\mathrm{kg}$, p.o.) reduced escape latencies on day $5(P<0.05)$, day $6(P<0.01)$, day $7(P<0.001)$ and swimming distances on day $6(P<0.01)$, day $7(P<0.001)$ when compare to scopolamine-treated group. In addition, MEXX (75 mg/ $\mathrm{kg}$, p.o.) reduced escape latencies on day $4(P<0.05)$, day $5(P<0.01)$, day 6, $7(P<0.001)$ and swimming distances on day $5(P<0.01)$ day $6,7(P<0.001)$ when compare to scopolamine-treated group. Finally, MEXX (100 mg/ $\mathrm{kg}$, p.o.) reduced escape latencies on day $4(P<0.01)$, day $5,6,7(P<0.001)$ and swimming distances on day 4,5 $(P<0.01)$ day $6,7(P<0.001)$ when compare to scopolamine-treated group. On the last day (day 8), the time in the target quadrant in scopolamine treated mice was significantly reduced compared to that of the vehicle-treated controls (Fig. 4c, $P<0.05$ ). Furthermore, the shorter time in the target quadrant induced by scopolamine was significantly reduced by MEXX (100 mg/kg, p.o.) (Fig. 4c, $P<0.05)$.

As shown in Fig. 5a, there was no significant difference in locomotor activities determined as total distance travel between vehicle-treated control, Scop $1.5 \mathrm{mg}$, and XX mice groups. Administrations of $\operatorname{MEXX}$ (50, 75 or $100 \mathrm{mg} / \mathrm{kg}$, p.o.) before the experiments had no effect on locomotor activity compared with those in the vehicle-treated control. In the sample experiment, no mouse 
Table $1{ }^{1} \mathrm{H}$ and ${ }^{13} \mathrm{C}$ NMR data for (3ß)-hopan-3-ol-28,22olide (1) in $\mathrm{CDCl}_{3}$

\begin{tabular}{|c|c|c|}
\hline \multirow[t]{2}{*}{ Position } & \multicolumn{2}{|c|}{ (3ß)-Hopan-3-ol-28,22-olide (1) } \\
\hline & $\delta_{\mathrm{C}}$, type & $\delta_{\mathrm{H}}(J$ in $\mathrm{Hz})$ \\
\hline $1 a$ & $39.1, \mathrm{CH}_{2}$ & $1.62, \mathrm{~m}$ \\
\hline $1 b$ & & $1.72, \mathrm{~m}$ \\
\hline 2 & $27.6, \mathrm{CH}_{2}$ & $1.61, \mathrm{~m}$ \\
\hline 3 & $79.1, \mathrm{CH}$ & $3.19, \mathrm{dd}(11.4,4.8)$ \\
\hline 4 & $41.0, C$ & - \\
\hline 5 & $55.6, \mathrm{CH}$ & $0.69, \mathrm{~m}$ \\
\hline 6 & $18.5, \mathrm{CH}_{2}$ & $1.56, \mathrm{~m}$ \\
\hline 7 & $34.2, \mathrm{CH}_{2}$ & $1.39, \mathrm{~m}$ \\
\hline 8 & $41.8, \mathrm{C}$ & - \\
\hline 9 & $50.9, \mathrm{CH}$ & $1.38, \mathrm{~m}$ \\
\hline 10 & $37.4, C$ & - \\
\hline 11 & $20.6, \mathrm{CH}_{2}$ & $1.51, \mathrm{~m}$ \\
\hline 12 & 27.0, $\mathrm{CH}_{2}$ & $1.62, \mathrm{~m}$ \\
\hline 13 & $37.1, \mathrm{CH}$ & $1.79, \mathrm{~m}$ \\
\hline 14 & $41.8, C$ & - \\
\hline $15 a$ & $33.8, \mathrm{CH}_{2}$ & $1.82, \mathrm{~m}$ \\
\hline $15 b$ & & $1.59, \mathrm{~m}$ \\
\hline $16 a$ & $26.5, \mathrm{CH}_{2}$ & $2.00, \mathrm{~m}$ \\
\hline $16 b$ & & $1.61, \mathrm{~m}$ \\
\hline 17 & $48.3, \mathrm{CH}$ & $1.62, \mathrm{~m}$ \\
\hline 18 & $48.7, C$ & - \\
\hline $19 a$ & $29.1, \mathrm{CH}_{2}$ & $2.41, \mathrm{dt}(13.3,3.5)$ \\
\hline $19 b$ & & $1.25-1.30, \mathrm{~m}$ \\
\hline 20 & $29.1, \mathrm{CH}_{2}$ & $1.25, \mathrm{~m}$ \\
\hline 21 & $42.6, \mathrm{CH}$ & $2.13, \mathrm{t}(4.4)$ \\
\hline 22 & $83.4, C$ & - \\
\hline 23 & $28.2, \mathrm{CH}_{3}$ & $0.96, \mathrm{~s}$ \\
\hline 24 & $15.9, \mathrm{CH}_{3}$ & $0.76, \mathrm{~s}$ \\
\hline 25 & $16.4, \mathrm{CH}_{3}$ & $0.83, \mathrm{~s}$ \\
\hline 26 & $15.5, \mathrm{CH}_{3}$ & $0.93, \mathrm{~s}$ \\
\hline 27 & $14.2, \mathrm{CH}_{3}$ & $0.94, \mathrm{~s}$ \\
\hline 28 & $175.9, C$ & - \\
\hline 29 & $30.3, \mathrm{CH}_{3}$ & $1.46, \mathrm{~s}$ \\
\hline 30 & $30.4, \mathrm{CH}_{3}$ & $1.32, \mathrm{~s}$ \\
\hline
\end{tabular}

groups showed significant differences in time spent exploring each identical object (Fig. 5b). On the other hand, the control and XX $100 \mathrm{mg}$ groups spent a significantly longer time exploring the new object than exploring the familiar one $(P<0.01$ paired $t$ test), while the XX $50 \mathrm{mg}$ and XX $75 \mathrm{mg}$ groups mouse showed a deficit in terms of the novel object recognition performance in the test phase session, as shown in Fig. 5c.

In this study, scopolamine significantly reduced spontaneous alternation (\%) in Y-maze test and time exploring the new object in object recognition test in scop $1.5 \mathrm{mg}$

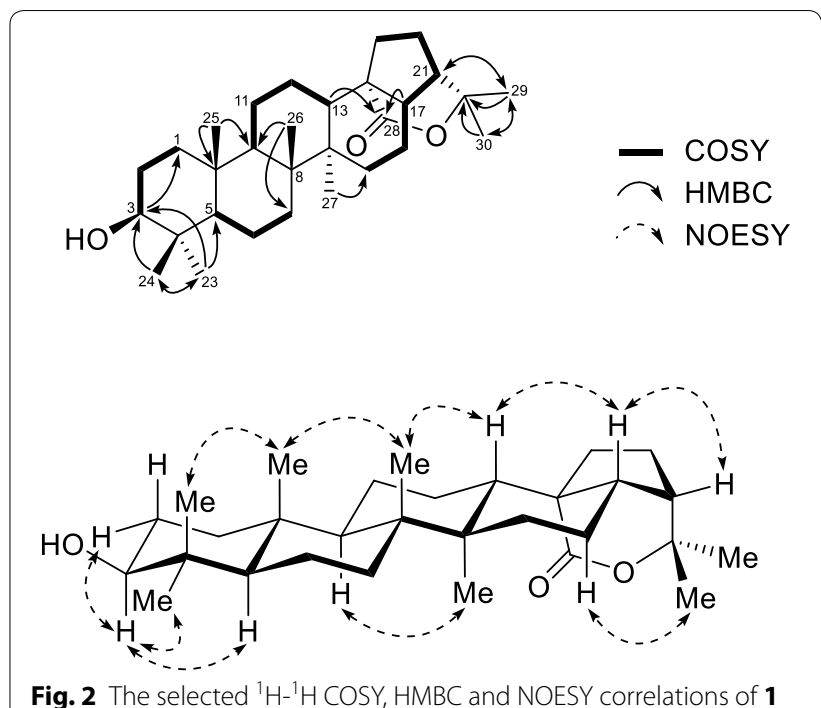

Table 2 Cholinesterase inhibitory activity of the isolated compounds

\begin{tabular}{|c|c|c|c|c|c|}
\hline \multirow{2}{*}{$\begin{array}{l}\text { Com- } \\
\text { pounds }\end{array}$} & \multicolumn{2}{|l|}{$I C_{50}(\mu M)^{a}$} & \multirow{2}{*}{$\begin{array}{l}\text { Com- } \\
\text { pounds }\end{array}$} & \multicolumn{2}{|l|}{$I C_{50}(\mu \mathrm{M})^{\mathrm{a}}$} \\
\hline & AChE & BChE & & AChE & BChE \\
\hline 1 & $79.5 \pm 1.1$ & $>100$ & 11 & $86.5 \pm 0.6$ & $>100$ \\
\hline 2 & $75.7 \pm 3.1$ & $>100$ & 12 & $77.3 \pm 0.8$ & $>100$ \\
\hline 3 & $>100$ & $>100$ & 13 & $54.4 \pm 3.4$ & $42.7 \pm 7.6$ \\
\hline 4 & $93.4 \pm 2.2$ & - & 14 & $>100$ & $>100$ \\
\hline 5 & $83.9 \pm 0.6$ & $>100$ & 15 & $>100$ & - \\
\hline 6 & - & - & 16 & $>100$ & $>100$ \\
\hline 7 & $62.0 \pm 2.2$ & - & 17 & $>100$ & - \\
\hline 8 & $94.6 \pm 1.5$ & $>100$ & 18 & $>100$ & $>100$ \\
\hline 9 & $84.9 \pm 1.2$ & $>100$ & 19 & $>100$ & - \\
\hline 10 & $>100$ & - & 20 & $>100$ & - \\
\hline Berberine & $0.67 \pm 0.0$ & $24.5 \pm 0.2$ & 21 & $>100$ & - \\
\hline
\end{tabular}

${ }^{a}$ Data are the average of 3 replicates \pm SD

group mice. These indicated that scopolamine induces impairment of short-term spatial and non-spatial working memory. In Morris water maze test, scopolamine impaired gradual decrease of escape latencies, swimming distances during training session and reduced the time spent in target quadrant during probe session. These observations suggest that scopolamine not only impairs the process of acquisition by producing anterograde amnesia, which subsequently affects the retrieval of these. Morris water maze test represents the model of memory especially spatial memory. During the training trials, mouse locates the hidden platform using spatial cues. This model is very helpful to analyze the reversal amnesic effect with investigational drug because 

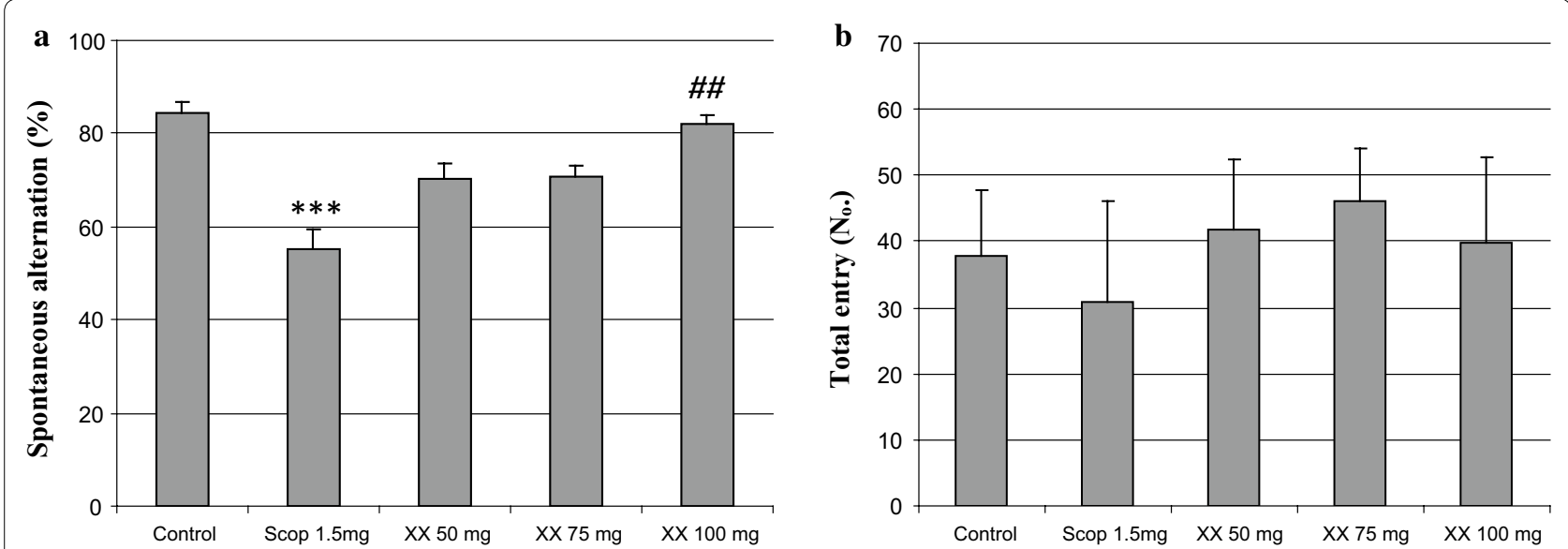

Fig. 3 The effects of MEXX on scopolamine-induced memory impairment in mice in the Y-maze task. Spontaneous alternation behavior (a) and numbers of arm entries $(\mathbf{b})$ during a 10 min session were recorded. Data represent mean \pm SEM $\left(n=12\right.$ per group) ${ }^{* * *} p<0.001$ versus the vehicletreated controls, $\#^{\#} P<0.01$ versus the scopolamine-treated group)
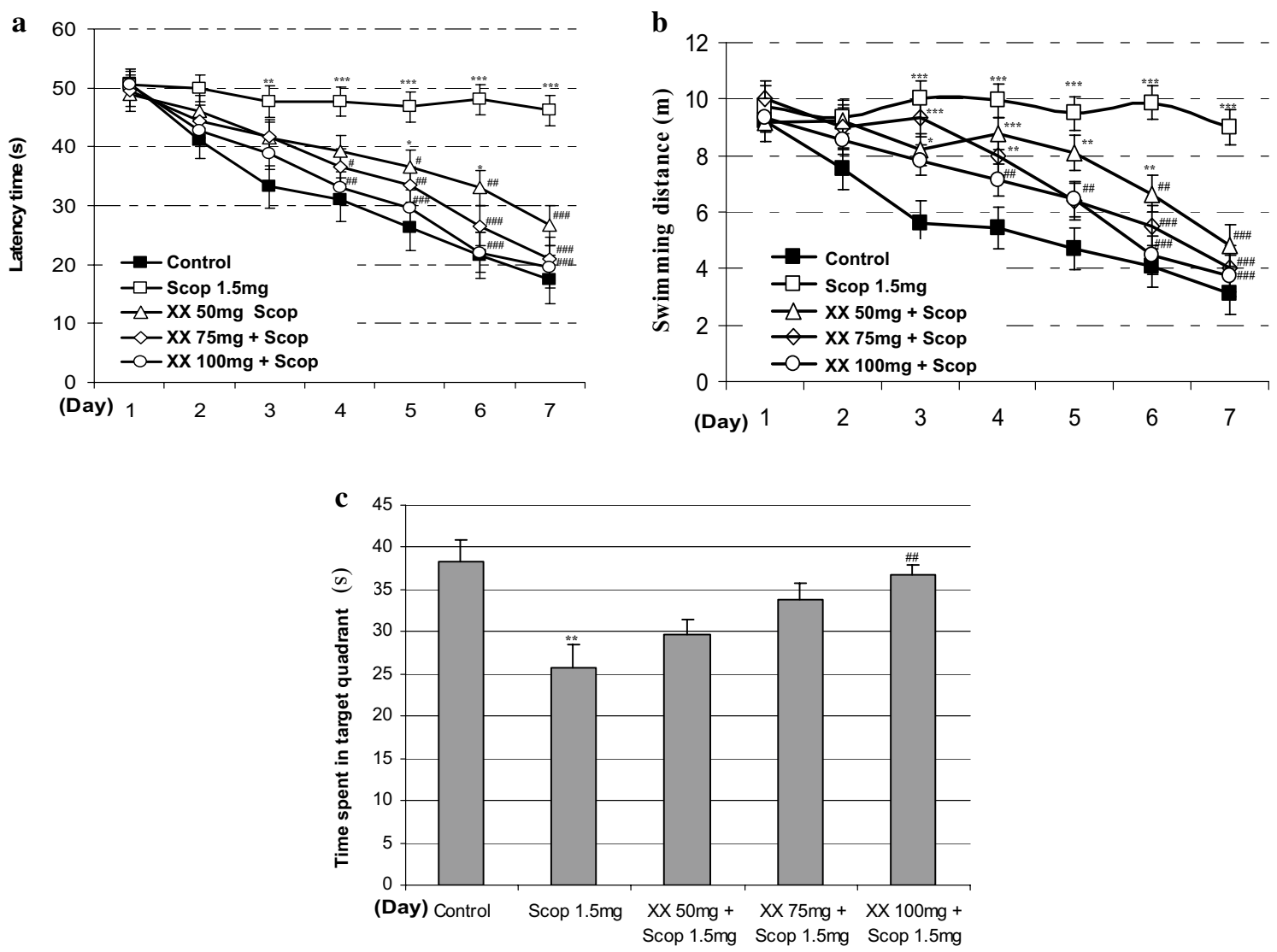

Fig. 4 The effects of MEXX on escape latencies (a), and swimming distance (b) during the training-trial sessions and on swimming times during the probe-trial session (c) in the Morris water maze task on scopolamine induced memory dysfunction in mice. Data represent mean \pm SEM $(n=12$ per group) ${ }^{*} P<0.05,{ }^{* *} P<0.01,{ }^{* *} P<0.001$ versus the vehicle-treated controls, ${ }^{\# \#} P<0.01$, \#\#P $<0.001$ versus the scopolamine-treated group) 

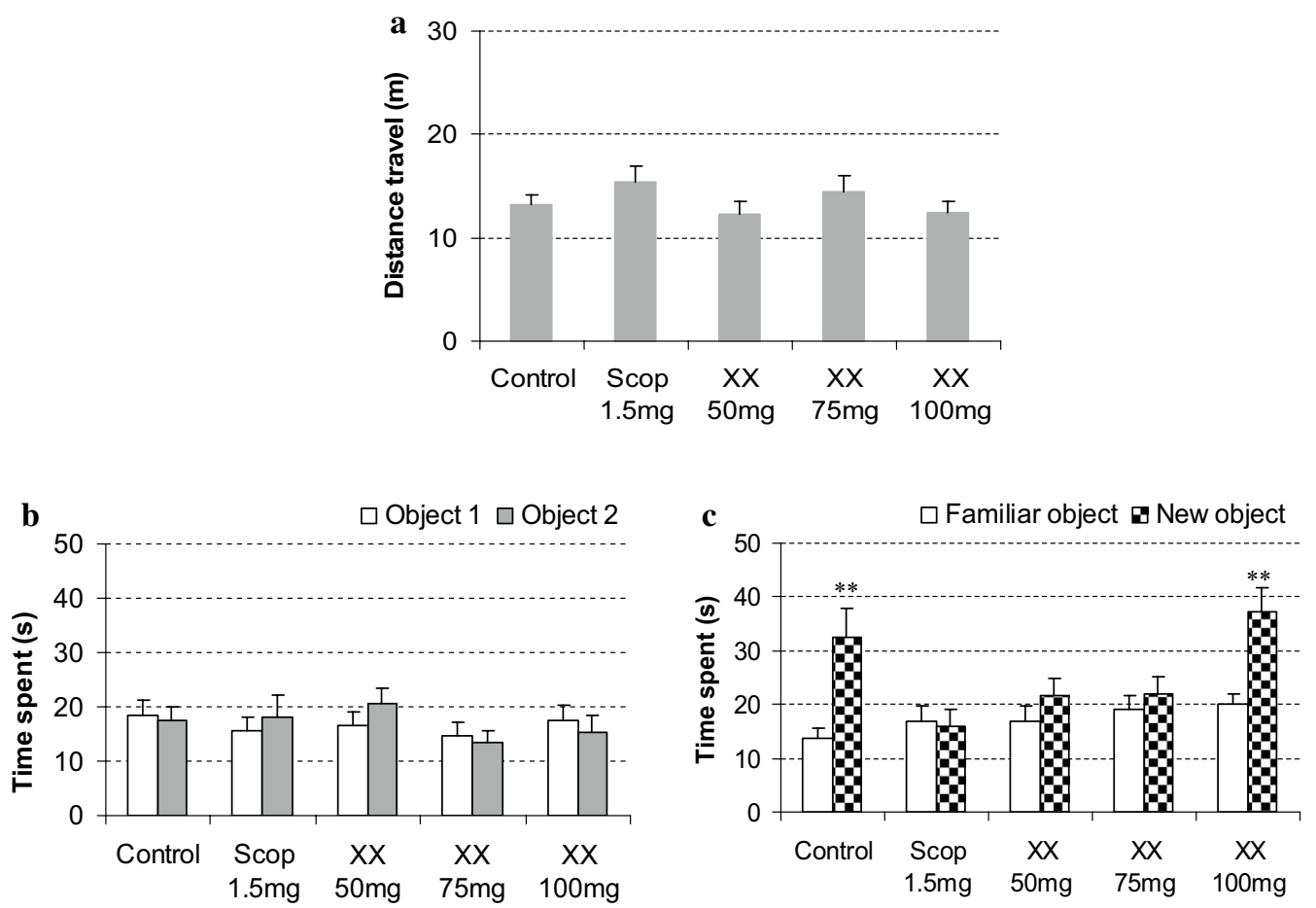

Fig. 5 Effects of MEXX on object recognition deficits in mice in the sample phase $(\mathbf{b})$ and the test phase $(\mathbf{c})$, while data of locomotor activities are shown in $(\mathbf{a})$. Each datum represents mean \pm SEM $(n=12)$. The ${ }^{* *} P<0.01$ versus time spent exploring a familiar object (paired $t$ test)

receptive trials with ongoing trials confirm the progress of reversal of amnesia [27-29].

In our experiment, administration of MEXX plus scopolamine-treated groups showed significantly shorter mean escape latencies and swimming distances than did the scopolamine-treated group in training session. The swimming time of the scopolamine-treated mice within the platform quadrant was significantly reduced by treating with MEXX $(100 \mathrm{mg} / \mathrm{kg})$ in probe session. This indicated that MEXX is able to protect mice from scopolamine-induced learning and memory (both acquisition and retrieval process) impairment as assessed by the Morris water maze test. The in vitro inhibitory activity on AChE and BChE of MEXX suggesting that the in vivo memory enhancing effect of MEXX due to its AChE inhibition in cells and tissues. The results are in correlations with those of previous studies on the effect of memory enhancing of some natural product such as: Black Maca, imperatorin, Lycium barbarum polysaccharides [27, 30-32].

Working memory is one of the short-term memories that could be impaired at an early stage of $\mathrm{AD}[2$, 29]. Previous reports have shown that Y-maze test is the experimental paradigms appropriate to evaluate antidementia activities of drugs including natural products $[29,33]$. Some plants exhibit the inhibitory activity on
AChE reduced spontaneous alternation (\%) in Y-maze test $[27,34]$. In our experiment, we employed Y-maze test to investigate effect of MEXX in short-term spatial working memory. The experimental results showed MEXX $(100 \mathrm{mg} / \mathrm{kg})$ improved scopolamine-induced decrease in spontaneous alternation (\%) while it did not affect in spontaneous locomotors. This suggests that MEXX alleviated the memory impairment induced by scopolamine injection.

The effect of the MEXX on cognitive impairment was further confirmed by using object recognition test [35]. According to the results, no significant difference in total time spent exploring two identical objects was observed between control and scop $1.5 \mathrm{mg}$ groups in sample phase session, indicating no differences in ability to recognize objects between animals. In the test phase session, the results showed that mice in the control group spent more time exploring the new object, whereas the scopolaminetreated mice showed no total time difference between familiar and new objects, indicating impairment of nonspatial object recognition memory. Administration of MEXX (100 mg/kg, p.o.) could significantly ameliorate scopolamin-induced recognition impairment against the new objects. This result is in correlation with other studies on Ptychopetalum olacoides [33], Acanthopanax trifoliatus [36], Lycium barbarum [31]. These plants inhibited 
$\mathrm{AChE}$ activity and improved performance in object recognition test in scopolamine treated mice.

Previous authors indicated that performance in Y-maze, object recognition task are impaired by anticholinergic drugs, as well as cholinergic neuronal lesions [32, 37, 38]. Conversely, improved performance in Y maze, object recognition was observed with drugs that enhance cholinergic activity, and inhibit AChE [27, 30]. Alzheimer's treatment drug such as piracetam and pramiracetam, were shown to improve learning, memory and cognition in Morris water maze, Y-maze and object recognition test [38]. Our results are consistent with the notion that acetylcholine is critical in the processes underlying attention, learning and memory, the aging brain $[3,4]$.

\section{Methods}

\section{General experimental procedures}

The UV spectra were obtained with a Shimadzu UV-1800 recording spectrophotometer. The IR spectra were measured with a Shimadzu IR-408 spectrophotometer in $\mathrm{CHCl}_{3}$ solutions. The NMR spectra were taken on a Bruker Avance III $500 \mathrm{MHz}$ spectrometer (Bruker Biospin) with tetramethylsilane (TMS) as an internal standard, and chemical shifts are expressed in $\delta$ values. The HR-ESI-MS was performed on a MicrO-QIITOF mass spectrometer (Bruker Daltonics). The ChE inhibitory reactions were recorded on 96-well microplates using a microplate reader (VersaMax ELISA, USA). Silica gel 60, 0.06-0.2 mm (70-230 mesh ASTM), for column chromatography was purchased from Scharlau (Barcelona, Spain). LiChroprep ${ }^{\circledR}$ RP-18 $(40-63 \mu \mathrm{m})$ for liquid chromatography was purchased from Merck KGaA (Germany). Analytical and preparative TLC were carried out on precoated Merck Kieselgel $60 \mathrm{~F}_{254}$ or $\mathrm{RP}-18 \mathrm{~F}_{254}$ plates (0.25 or $0.5 \mathrm{~mm}$ thickness).

\section{Animals and chemicals}

Male Swiss mice (age, 8 weeks; weight, 25-27 g) were purchased from Military Medical University (Hanoi, Vietnam) and housed in a regulated environment $\left(21 \pm 2{ }^{\circ} \mathrm{C}, 12 \mathrm{~h}\right.$ light/dark cycle, light period starting at $7 \mathrm{AM}$ ) with free access to food and water. Acetylcholinesterase (AChE) (EC 3.1.1.7), butyrylcholinesterase (BChE) (EC 3.1.1.8) and scopolamine hydrobromide $(>98 \%)$ were obtained from Sigma-Aldrich Pte Ltd (Nucleos, Singapore). Dithiobisnitrobenzoate ( $>99 \%$ ), berberine $(>95 \%)$ and DMSO were purchased from Merck (Darmstadt, Germany). Other chemicals were of the highest grade available.

\section{Plant material}

The wood of $X$. xylocarpa was collected in Dak Lak province, Vietnam, in February 2012 and was identified by
Dr. Truong LH, Southern Institute of Ecology, Vietnam Academy of Science and Technology. A voucher sample of the wood (P0046) has been deposited at the Department of Analytical Chemistry, Faculty of Chemistry, University of Science, Vietnam National UniversityHochiminh City.

\section{Extraction and isolation}

Dried wood $(9.0 \mathrm{~kg})$ of $X$. xylocarpa was extracted with $\mathrm{MeOH}(15 \mathrm{~L}$, reflux, $3 \mathrm{~h} \times 3)$ to yield $480 \mathrm{~g}$ of methanolic extract (MEXX). The MeOH extract was suspended in $\mathrm{H}_{2} \mathrm{O}$ and partitioned successively with hexane, EtOAc, and $\mathrm{BuOH}$ to yield hexane (21 g), EtOAc (53 g), BuOH $(180 \mathrm{~g})$, and remaining aqueous $(226 \mathrm{~g})$ fractions, respectively. The EtOAc fraction (53 g) was subjected to silica gel column chromatography $(10 \times 120 \mathrm{~cm})$, eluted with $\mathrm{MeOH} / \mathrm{CHCl}_{3}(0-50 \%)$ yielding thirteen fractions (fr.A, $0.4 \mathrm{~g}$; fr.B, 0.5 g; fr.C, 0.9 g; fr.D, 7.8 g; fr.E, 2.1 g; fr.F, 3.2 g; fr.G, 1.9 g; fr.H, 1.9 g; fr.I, 1.2 g; fr.J, 0.3 g; fr.K, $4.1 \mathrm{~g}$; fr.L, $7.8 \mathrm{~g}$ and fr.M, $20.5 \mathrm{~g})$. Fraction fr.B $(0.5 \mathrm{~g})$ was applied to silica gel column chromatography $(2 \times 80 \mathrm{~cm})$, eluted with EtOAc/hexane (0-80 \%) to give four subfractions (fr.B1-B5). Subfractions fr.B2 and fr.B3 were rechromatographed on a silica gel column with EtOAc/ hexane as eluent to give compounds $\mathbf{2}(17.6 \mathrm{mg})$, and $\mathbf{1 2}$ $(2.4 \mathrm{mg})$. Fraction fr.C $(0.7 \mathrm{~g})$ was also subjected to silica gel column chromatography $(2 \times 80 \mathrm{~cm})$, eluted with EtOAc/hexane (0-80 \%) to afford three subfractions (fr. C1-C3). Subfraction fr.C1 was separated by column chromatography with EtOAc/hexane as eluent (0-60\%) and purified by preparative TLC to obtain $5(3.5 \mathrm{mg})$ and $6(6.3 \mathrm{mg})$. Subfraction fr.C2 was further separated by silica gel column chromatography, eluted with EtOAc/hexane and $\mathrm{CHCl}_{3} /$ hexane to give compound $\mathbf{1 1}$ $(2.6 \mathrm{mg})$. Fraction fr.D (7.8 g) was dissolved in $\mathrm{CHCl}_{3} /$ hexane (20:80) to gain the precipitation of $\mathbf{1 0}(2.4 \mathrm{~g})$, the remaining part was further separated by silica gel column chromatography $(5 \times 80 \mathrm{~cm})$ with EtOAc/hexane $(0-80 \%)$ to yield four subfractions (fr.D1-D4). Subfraction fr.D1 was rechromatographed on silica gel column chromatography with EtOAc/hexane to give $3(2.8 \mathrm{mg})$ and $8(3.1 \mathrm{mg})$. Subfraction fr.D3 was subjected to silica gel column chromatography and successively eluted with acetone/hexane (0-80 \%), EtOAc/ $\mathrm{CHCl}_{3}(0-50 \%)$, acetone $/ \mathrm{CHCl}_{3}(0-80 \%)$, and then followed by preparative TLC with acetone/hexane (8:92) to afford $\mathbf{1}(15.7 \mathrm{mg}), \mathbf{4}$ $(19.3 \mathrm{mg})$ and $9(3.2 \mathrm{mg})$. Fraction fr.E $(2.1 \mathrm{~g})$ was separated by silica gel column chromatography $(3 \times 80 \mathrm{~cm})$ with $\mathrm{MeOH} / \mathrm{CHCl}_{3}(0-30 \%)$ as eluent to yield four subfractions (fr.E1-E4). Subfractions fr.E1 and fr.E2 were purified by preparative TLC with EtOAc/hexane (20:80) and acetone/hexane (6:94) to yield 13 (14.6 mg), $14(5.8 \mathrm{mg})$ and $15(10.2 \mathrm{mg})$. Subfraction fr.E3 was 
further separated by silica gel column chromatography with $\mathrm{MeOH} / \mathrm{CHCl}_{3}$ to give four subfraction (fr.E3.1E3.4). Subfraction fr.E3.1 was rechromatographed on a silica gel column with EtOAc/hexane as eluent (0-60 \%) to afford compound $\mathbf{1 6}$ (5.6 $\mathrm{mg})$. The insoluble subfraction fr.E3.4 was dissolved in acetone/hexane (10:90) and recrystallized to yield $\mathbf{1 8}(15.9 \mathrm{mg})$. Fraction fr.F (3.2 g) was further separated by silica gel column chromatography $(3 \times 80 \mathrm{~cm})$ eluted with EtOAc/hexane $(0-50 \%)$ and $\mathrm{MeOH} / \mathrm{CHCl}_{3}(0-30 \%)$ and to give 19 (3.6 mg). Fraction fr.G (1.9 g) was subjected to silica gel column chromatography $(3 \times 80 \mathrm{~cm})$ eluted with $\mathrm{MeOH} / \mathrm{CHCl}_{3}(0-60 \%)$ to give four subfractions (fr.G1-G4). Subfraction fr.G1 and fr.G2 was rechromatographed on silica gel column with EtOAc/hexane and $\mathrm{CHCl}_{3} /$ hexane and respectively purified by preparative TLC with acetone $/ \mathrm{CHCl}_{3}(10: 90)$ and $\mathrm{MeOH} / \mathrm{CHCl}_{3}(10: 90)$ to give $7(156.3 \mathrm{mg})$ and 21 (3.5 mg), respectively. Compound 19 (160 mg) was recrystallised from the insoluble fraction of fr.I $(1.2 \mathrm{~g})$ in acetone/hexane (10:90), and the remaining part was applied to silica gel column chromatography $(2 \times 80 \mathrm{~cm})$ with $\mathrm{MeOH} / \mathrm{CHCl}_{3}$ as eluent (0-50\%), the eluate was concentrated and crystallised in acetone/hexane (10:90) to afford 17 (10.2 $\mathrm{mg})$.

(3ß)-Hopan-3-ol-28,22-olide (1): White amophous powder, IR $\left(\mathrm{CHCl}_{3}\right) \mathrm{cm}^{-1}$ : 3310, 1730, 1170, 1100. ${ }^{1} \mathrm{H}-\mathrm{NMR}\left(\mathrm{CDCl}_{3}, 500 \mathrm{MHz}\right)$ and ${ }^{13} \mathrm{C}-\mathrm{NMR}\left(\mathrm{CDCl}_{3}\right.$, $125 \mathrm{MHz}$ ), see Table 1. HR-ESI-MS $\mathrm{m} / z: 457.3674$ $[\mathrm{M}+\mathrm{H}]^{+}$and $479.3482[\mathrm{M}+\mathrm{Na}]^{+}\left(\right.$Calcd for $\mathrm{C}_{30} \mathrm{H}_{49} \mathrm{O}_{3}$, 457.3682; $\mathrm{C}_{30} \mathrm{H}_{48} \mathrm{O}_{3} \mathrm{Na}$, 479.3501) (for further information, see Additional file 1).

\section{$\mathrm{AChE}$ and $\mathrm{BChE}$ inhibition assay}

The inhibitory activities of the ChEs were measured using a modified Ellman's method [39]. Acetylthiocholine and butyrylthiocholine were used as substrates to examine the inhibitory effect of sample on the AChE and $\mathrm{BChE}$ action, respectively. The reaction mixture contained: $140 \mu \mathrm{L}$ of sodium phosphate buffer ( $\mathrm{pH} 8.0)$; $20 \mu \mathrm{L}$ of tested sample solution; and $20 \mu \mathrm{L}$ of either $\mathrm{AChE}$ or BChE solution (5 units $/ \mathrm{mL}$ ), which were mixed and incubated at room temperature for $15 \mathrm{~min}$. The reactions were initiated by the addition of $10 \mu \mathrm{L}$ of dithiobisnitrobenzoate (DTNB) and $10 \mu \mathrm{L}$ of either acetylthiocholine or butyrylthiocholine, respectively. The hydrolysis of AChE or BChE was monitored at $412 \mathrm{~nm}$ based on the formation of yellow 5-thio-2-nitrobenzoate anion from the reaction of DTNB with thiocholine, which was released by enzymatic hydrolysis of either $\mathrm{AChE}$ or BChE. All tested samples and the positive control, berberine [40], were dissolved in $10 \%$ DMSO (analytical grade). The reaction was performed in triplicate and recorded in 96-well microplates using a microplate reader (VersaMax ELISA, USA). Percent inhibition was calculated from $(1-S / E) \times 100$, where $E$ and $S$ were the enzyme activities with and without the tested sample, respectively. The ChE inhibitory activity of each sample was expressed in terms of the $\mathrm{IC}_{50}$ value $(\mu \mathrm{M}$ required to inhibit the hydrolysis of the substrate, $\mathrm{AChE}$ or $\mathrm{BChE}$, by $50 \%$ ), as calculated from the logarithmic dose-inhibition curve.

\section{Animal grouping and drug treatment}

The male Swiss mice were randomly assigned to five treatment groups ( $\mathrm{n}=12$ per group): (1) Control (Saline), (2) Scop $1.5 \mathrm{mg}$ (scopolamine $1.5 \mathrm{mg} / \mathrm{kg} /$ day), (3) XX $50 \mathrm{mg}$ (MEXX $50 \mathrm{mg} / \mathrm{kg} /$ day + scopolamine $1.5 \mathrm{mg} / \mathrm{kg} /$ day), (4) XX $75 \mathrm{mg}$ (MEXX $75 \mathrm{mg} / \mathrm{kg} /$ day + scopolamine $1.5 \mathrm{mg} / \mathrm{kg} /$ day) and (5) XX $100 \mathrm{mg}$ (MEXX $100 \mathrm{mg} / \mathrm{kg} /$ day + scopolamine $1.5 \mathrm{mg} / \mathrm{kg} /$ day). MEXX was dissolved in saline and administered by oral gavage (p.o.). Scopolamine was also dissolved in saline and administered by intraperitoneal (i.p.) injection. MEXX was administered $60 \mathrm{~min}$ before the trial, and scopolamine was injected $30 \mathrm{~min}$ before the trial.

\section{Morris water Y-maze test}

The Morris water maze is a black circular pool $(80 \mathrm{~cm}$ in diameter and $35 \mathrm{~cm}$ in height) with a featureless inner surface. The circular pool was filled with water and nontoxic water-soluble black dye $\left(20 \pm 1{ }^{\circ} \mathrm{C}\right)$. The pool was divided into four quadrants of equal area. A transparent platform $(4 \mathrm{~cm}$ in diameter and $18 \mathrm{~cm}$ in height) was centered in one of the four quadrants of the pool and submerged $1 \mathrm{~cm}$ below the water surface so that it was invisible at water level. The pool was located in a test room, which contained various prominent visual cues. The position of platform for escape and the visual cues remained unchanged throughout the experiments. The location of each swimming mouse, from the start position to the platform, was monitored by a video tracking system (ANY-maze, Stoelting, USA). In the water maze experiments, the day prior to the experiment was dedicated to swim training for $60 \mathrm{~s}$ in the absence of the platform. During the seven subsequent days, the mice were given four training-trials per session per day and an intertrial interval of $2 \mathrm{~min}$. For each training-trial, mice were placed in the water facing the pool wall in a randomly selected pool quadrant, the escape latencies and distance swim were recorded. These parameters were averaged for each day and for each mouse. Once the mouse located the platform, it was permitted to remain on it for $10 \mathrm{~s}$. If the mouse did not locate the platform within $60 \mathrm{~s}$, it was placed on the platform for $10 \mathrm{~s}$ and then removed from the. On day 8 , the probe test involved removing the platform from the pool. That test was performed with 
the cut-off time of $120 \mathrm{~s}$. The point of entry of the mouse into the pool was changed each trial thereafter. Mice were treated with saline or MEXX $(50,75$ or $100 \mathrm{mg} / \mathrm{kg}$, p.o.) given before the training trial. After $30 \mathrm{~min}$, amnesia was induced in mice with scopolamine $(1.5 \mathrm{mg} / \mathrm{kg})$ given intraperitoneal injection. All mice were tested for spatial memory 30 min after scopolamine treatment.

\section{Y-maze test}

The Y-maze is a three-arm maze with equal angles between all arms, which were $35 \mathrm{~cm}$ length and $5 \mathrm{~cm}$ width, with walls $10 \mathrm{~cm}$ high. The maze floor and walls were constructed from dark grey polyvinyl plastic. Mice were initially placed within one arm, and the sequence and number of arm entries were recorded 10-min period for each mouse and analyzed monitored by a video tracking system (ANY-maze, Stoelting, USA). One hour before the test, mice in control group and scop $1.5 \mathrm{mg}$ group received distilled water and other mice were administered MEXX (50, 75, or $100 \mathrm{mg} / \mathrm{kg}$, p.o.). After $30 \mathrm{~min}$, memory impairment was induced by administering scopolamine $(1.5 \mathrm{mg} / \mathrm{kg}$, i.p.). Arms were cleaned between tests to remove odors and residues by diluted $10 \%$ ethanol. Alternation behavior was determined from successive entries into three different arms (e.g., $A B C, C A B$, or BCA). An arm entry by the mice was defined as placing all four paws within a boundary of the arm. The alternation score (\%) for each mouse was defined as the ratio of the actual number of alternations to the possible number (defined as the total number of arm entries minus two) multiplied by 100 as shown by the following equation: $\%$ Alternation $=[($ Number of alternations $) /($ Total arm entries -2$)] \times 100$. The number of arm entries was used as an indicator of locomotor activity.

\section{Object recognition test}

The task took place in a to an open-field box $(45 \times 45 \times 50 \mathrm{~cm})$. Firstly, all animals were submitted to a habituation session, freely exploring the object free open field for $5 \mathrm{~min}$. Twenty-four hours later, the sample phase session took place by placing individual mice for $5 \mathrm{~min}$ at the field in which two identical objects (A1 and A2; identical toys) were placed in a symmetrical position about $10 \mathrm{~cm}$ away from the wall; exploration was defined as the time spent sniffing or touching the object with the nose and/or forepaws. Test phase session were performed $24 \mathrm{~h}$ after training, when mice were allowed to explore the open field for $5 \mathrm{~min}$ in the presence of one familiar (A) and one novel (B) object. One hour before test phase session, mice were administered MEXX (50, 75, or $100 \mathrm{mg} /$ $\mathrm{kg}$, p.o.). The control group received distilled water. After $30 \mathrm{~min}$, memory impairment was induced by administering scopolamine $(1.5 \mathrm{mg} / \mathrm{kg}$, i.p.). All objects presented similar textures and sizes, but distinctive shapes; after each trial objects were washed with $10 \%$ ethanol to discard smells or residues. The exploration time and frequencies were recorded, $\mathrm{n}=12$ per group.

\section{Statistical analysis}

The results of the behavioral studies are expressed as mean \pm SEM, Y-maze test spontaneous alternation (\%), object recognition test distance travel and Morris water maze test probe-trial swimming times were analyzed by one-way analysis of variance (ANOVA) followed by Tukey's post hoc for multiple comparisons. The object recognition test time spent exploring a familiar and novel object in sample and test phase were analyzed by pair t-test. The Morris water maze test training-trial escape latencies and distance were analyzed by two-way ANOVA repeated followed by Tukey's post hoc analysis using the day as one variable and treatment as a second. Statistical significance was set at $P<0.05$.

\section{Conclusions}

In conclusion, a new hopan-type triterpenoid, $(3 \beta)$ hopan-3-ol-28,22-olide (1) was isolated together with twenty known compounds (2-21). Compound 1, 2, 4, 5, 7-9, and 11-13 exhibited potent acetylcholinesterase (AChE); and compound 13 was also shown anti-butyrylcholinesterase (BChE) activity. The cognitive-enhancing effect of the MEXX on amnesic mice induced by scopolamine in vivo. It is noteworthy that MEXX is effective when administered orally to mice, experimental results are consistent with the traditional use of this medicinal plant species, the data here reported justify further studies with this plant extract in the context of treating attention and cognitive deficits associated with neurodegenerative diseases.

\section{Additional file}

Additional file 1. One-dimensional (1D) and two-dimensional (2D) nuclear magnetic resonance (NMR) and mass spectrometry (MS) of a new compound (1).

\section{Authors' contributions}

LMTL, MTTN, NTN and MVC designed research; LMTL, HXN, HTN, NMN, BSM, JAK, and JSC performed research; LMTL, PHD and NTN analyzed spectral data; TMH, HXN, HTN, and NMN and MVC analyzed biological data; LMTL, MVC and MTTN wrote the paper. All authors read and approved the final manuscript.

\footnotetext{
Author details

${ }^{1}$ Faculty of Chemistry, University of Science, Vietnam National UniversityHochiminh City, 227 Nguyen Van Cu, District 5, Hochiminh City, Vietnam. ${ }^{2}$ Vietnam Military Medical University, Hadong District, Hanoi, Vietnam. ${ }^{3}$ College of Pharmacy, Catholic University of Daegu, Gyeongsan, Gyeongsangbuk 712-702, Republic of Korea. ${ }^{4}$ College of Pharmacy, Research Institute of Pharmaceutical Sciences, Kyungpook National University, Daegu 702-701, Republic of Korea. ${ }^{5}$ Department of Food Science and Nutrition, Pukyong National
} 
University, Busan 608-737, Republic of Korea. ${ }^{6}$ Cancer Research Laboratory, Vietnam National University-Hochiminh City, Hochiminh City, Vietnam.

\section{Acknowledgements}

This work was supported by Grant 106-YS.05-2013.24 from Vietnam's National Foundation for Science and Technology Development (NAFOSTED).

\section{Competing interests}

The authors declare that they have no competing interests.

Received: 27 April 2016 Accepted: 28 July 2016

Published online: 03 August 2016

\section{References}

1. Blennow K, de Leon MJ, Zetterberg H (2006) Alzheimer's disease. Lancet 368:387-403

2. Cummings JL (2004) Alzheimer's disease. N Engl J Med 351:56-67

3. McGleenon BM, Dynan KB, Passmore AP (1999) Acetylcholinesterase inhibitors in Alzheimer's disease. Br J Clin Pharmacol 48:471-480

4. Garcia-Ayllon MS, Small DH, Avila J, Saez-Valero J (2011) Revisiting the role of acetylcholinesterase in Alzheimer's disease: cross-talk with P-tau and beta-amyloid. Front Mol Neurosci 4:1-9

5. Vo VC (2011) Dictionary of Vietnamese medicinal plants. Medicine Publisher, Hanoi

6. Nakmee PS, Khuntong S, Nuengchamnong N (2016) Phytochemical constituents with antimicrobial and antioxidant activities from Xylia xylocarpa (Roxb.) Taub. Sawdust extracts. Chiang Mai J Sci 43:11-21

7. Burns D, Reynolds WF, Buchanan G, Reese PB, Enriquez RG (2000) Assignment of ${ }^{1} \mathrm{H}$ and ${ }^{13} \mathrm{C}$ spectra and investigation of hindered side-chain rotation in lupeol derivatives. Magn Reson Chem 38:488-493

8. Lee CK (1998) A new norlupene from the leaves of Melaleuca leucadendron. J Nat Prod 61:375-376

9. Tijjani A, Ndukwe IG, Ayo RG (2012) Isolation and characterization of lup-20(29)-ene-3,28-diol (Betulin) from the stem-bark of Adenium obesum (Apocynaceae). Trop J Pharm Res 11:259-262

10. Abdel Bar FM, Zaghloul AM, Bachawal SV, Sylvester PW, Ahmad KF, El Sayed KA (2008) Antiproliferative triterpenes from Melaleuca ericifolia. J Nat Prod 71:1787-1790

11. Hassan RA, Hassan EM, Brahim NA, Nazif NM (2015) Triterpenes and cytotoxic activity of Acokanthera oblongifolia Hochst. growing in Egypt. Res J Pharm Biol Chem Sci 6:1677-1686

12. Satiraphan M, Pamonsinlapatham P, Sotanaphun U, Sittisombut $C$ Raynaud F, Garbay C, Michel S, Cachet X (2012) Lupane triterpenes from the leaves of the tropical rain forest tree Hopea odorata Roxb. and their cytotoxic activities. Biochem Syst Ecol 44:4073-4412

13. Maillard M, Adewunmi CO, Hostettmann K (1992) A triterpene glycoside from the fruits of Tetrapleura tetraptera. Phytochemistry 31:1321-1323

14. Salvador JA, Pinto RM, Santos RC, Le Roux C, Beja AM, Paixao JA (2009) Bismuth triflate-catalyzed Wagner-Meerwein rearrangement in terpenes. Application to the synthesis of the 18alpha-oleanane core and A-neo-18alpha-oleanene compounds from lupanes. Org Biomol Chem 7:508-517

15. Achari B, Pakrashi SC (1976) Studies on Indian medicinal plants-XXXIX reinvestigation of the lactones and bromo derivative of betulinic acid. Tetrahedron 32:741-744

16. Cui XR, Tsukada M, Suzuki N, Shimamura T, Gao L, Koyanagi J, Komada F, Saito $S$ (2008) Comparison of the cytotoxic activities of naturally occurring hydroxyanthraquinones and hydroxynaphthoquinones. Eur J Med Chem 43:1206-1215

17. Peng W, Han T, Liu Q, Qin L (2011) Chemical co0nstituents from aerial part of Atractylodes macrocephala. Zhongguo Zhongyao Zasshi 36:578-581

18. Prachayasittikul S, Suphapong S, Worachartcheewan A, Lawung R, Ruchirawat S, Prachayasittikul V (2009) Bioactive metabolites from Spilanthes acmella Murr. Molecules 14:850-867

19. Galland S, Mora N, Abert-Vian M, Rakotomanomana N, Dangles O (2007) Chemical synthesis of hydroxycinnamic acid glucosides and evaluation of their ability to stabilize natural colors via anthocyanin copigmentation. J Agric Food Chem 55:7573-7579
20. X-h Cai, Xie B, Guo H (2006) Synthesis and evaluation of methyl 2-methoxycarbonyl-3-phenylpropionate derivatives as a new type of angiotensin converting enzyme inhibitors. Can J Chem 84:1110-1113

21. Lee $H$, Lee $H$, Lee $K$, Kang H, Lee D, Khan M (2010) Triterpene saponins and other constituents from Fatsia japonica. Chem Nat Compd 46:499-501

22. Chatsumpun M, Sritularak B, Likhitwitayawuid K (2010) Phenolic compounds from stem wood of Millettia leucantha. Chem Nat Compd 46:634-635

23. Pouységu L, Sylla T, Garnier T, Rojas LB, Charris J, Deffieux D, Quideau S (2010) Hypervalent iodine-mediated oxygenative phenol dearomatization reactions. Tetrahedron 66:5908-5917

24. Li-qin W, Rong H, Fu-chi Z, Qiu-xiang F, Ye-gao C (2011) Chemical constituents of Combretum punctatum spp. squamosum. Chem Nat Compd 47:470-471

25. Nakane T, Arai Y, Masuda K, Ishizaki Y, Ageta H, Shiojima K (1999) Fern constituents: six new triterpenoid alcohols from Adiantum capillus-veneris. Chem Pharm Bull 47:543-547

26. Kamaya R, Mori T, Shoji K, Ageta H, Chang H, Hsu H (1991) Fern constituents: triterpenoids from Oleandra wallichii. Yakugaku Zasshi 111:120-125

27. Rubio J, Dang H, Gong M, Liu X, Chen SL, Gonzales GF (2007) Aqueous and hydroalcoholic extracts of Black Maca (Lepidium meyenii) improve scopolamine-induced memory impairment in mice. Food Chem Toxicol 45:1882-1890

28. Vorhees CV, Williams MT (2006) Morris water maze: procedures for assessing spatial and related forms of learning and memory. Nat Protoc 1:848-858

29. Whishaw IQ, Kolb B (2004) The behavior of the laboratory rat. Oxford University Press, Oxford

30. Budzynska B, Boguszewska-Czubara A, Kruk-Slomka M, SkalickaWozniak K, Michalak A, Musik I, Biala G (2015) Effects of imperatorin on scopolamine-induced cognitive impairment and oxidative stress in mice. Psychopharmacology 232:931-942

31. Chen W, Cheng X, Chen J, Yi X, Nie D, Sun X, Qin J, Tian M, Jin G, Zhang X (2014) Lycium barbarum polysaccharides prevent memory and neurogenesis impairments in scopolamine-treated rats. PLOS ONE 9:1-13

32. Ennaceur A, Meliani K (1992) Effects of physostigmine and scopolamine on rats' performances in object-recognition and radial-maze tests. Psychopharmacology 109:321-330

33. Gotz J, Ittner LM (2008) Animal models of Alzheimer's disease and frontotemporal dementia. Nat Rev Neurosci 9:532-544

34. Kwon SH, Kim HC, Lee SY, Jang CG (2009) Loganin improves learning and memory impairments induced by scopolamine in mice. Eur J Pharmacol 619:44-49

35. Antunes M, Biala G (2012) The novel object recognition memory: neurobiology, test procedure, and its modifications. Cogn Process 13:93-110

36. Sithisarn P, Rojsanga P, Jarikasem S, Tanaka K, Matsumoto K (2013) Ameliorative effects of Acanthopanax trifoliatus on cognitive and emotional deficits in olfactory bulbectomized mice: an animal model of depression and cognitive deficits. Evid Based Complement Alternat Med 2013:1-10

37. Wirths O, Bayer TA (2010) Neuron loss in transgenic mouse models of Alzheimer's disease. Int J Alzheimers Dis 2010:1-6

38. Bartolini L, Casamenti F, Pepeu G (1996) Aniracetam restores object recognition impaired by age, scopolamine, and nucleus basalis lesions. Pharmacol Biochem Behav 53:277-283

39. Ellman GL, Courtney KD, Andres V Jr, Feather-Stone RM (1961) A new and rapid colorimetric determination of acetylcholinesterase activity. Biochem Pharmacol 7:88-95

40. Lee I, Ahn B, Choi J, Hattori M, Min B, Bae K (2011) Selective cholinesterase inhibition by lanostane triterpenes from fruiting bodies of Ganoderma lucidum. Bioorg Med Chem Lett 21:6603-6607 